\title{
Movimentos sociais contemporâneos no Brasil: a face invisível das Jornadas de Junho de 2013
}

\author{
Linda M. P. Gondim \\ Universidade Federal do Ceará, Fortaleza-CE, Brasil. \\ Email: lindagondim@uol.com.br
}

\begin{abstract}
Resumo: Analisa-se as manifestações que irromperam em centenas de cidades brasileiras em junho de 2013, cujo estopim foi a brutal repressão aos protestos contra o aumento das passagens de transportes coletivos em São Paulo. A rápida multiplicação dos protestos foi causada, principalmente, pela insatisfação com a política institucional, a corrupção e a escassez de investimentos públicos em educação e saúde, em contraste com aqueles destinados a megaeventos esportivos sediados pelo Brasil (Copa das Confederações de 2013, Copa do Mundo de 2014 etc.). Argumenta-se que a gênese espontânea das jornadas de junho tem sido superestimada, pois nelas tiveram participação ativa movimentos sociais preexistentes, cujas ações são eram massivas, nem amplamente publicizadas (Movimento Passe Livre, Comitês Populares da Copa e outros). Esses movimentos, tanto quanto as jornadas de junho de 2013, têm pautas e participantes heterogêneos. Em ambos os casos, não há centros formais de comando e as articulações são viabilizadas pela internet.
\end{abstract}

Palavras Chave: jornadas de junho; movimentos sociais urbanos; movimento passe livre; governos do pt.

\section{Movimientos sociales en Brasil contemporaneo: la face invisible de las protestas de junio de 2013}

Resumen: Se analizarán las manifestaciones que irrumpieron en cientos de ciudades brasileñas en junio de 2013, cuyo apogeo fue la brutal represión policial a las protestas contra el aumento de tarifas de transportes colectivos en São Paulo. La rápida multiplicación de las protestas fue causada principalmente por la insatisfacción con la política institucional, la corrupción y la escasez de inversiones públicas en educación y salud, en contraste a aquellas destinadas a grandes eventos deportivos ocurridos en Brasil (Copa Confederaciones de 2013, Mundial de 2014, y otros). Se argumenta que la génesis espontánea de tales protestas fue sobrestimada, pues movimientos sociales preexistentes tuvieron una participación activa en ellas, y sus acciones no eran masivas, tampoco ampliamente publicitadas (Movimiento "PasseLivre”, Comités Populares del Mundial, y otros). Estos movimientos, así como las manifestaciones, tienen pautas y participantes heterogéneos. En ambos casos, no hay centros formales de comando, siendo sus articulaciones viabilizadas por internet.

Palabras clave: Jornadas de junio; Movimientos sociales urbanos; Movimiento passelivre; Gobiernos del pt. 


\title{
Social movements in contemporary Brazil: the invisible face of the June 2013 protests
}

\begin{abstract}
This article analyses protests that came out in hundreds of Brazilian cities in June 2013. They burst after brutal repression against demonstrations, after the rise of public transportation fares in São Paulo. Protests spread was caused, principally, by dissatisfaction with institutional politics, corruption and scarcity of public investments in education and health, in contrast to investments in sports events that would take place in Brazil (the 2013 Soccer Confederation Cup, the 2014 Soccer World Cup and others). The papers' argument is that the spontaneous genesis of the June Journeys has been overestimated, since previous social movements had active participation in them. These movements's actions were neither massive nor broadly publicized (Free Fare Movement, 2014 Soccer World Cup Popular Committees, and others). Like the June Journeys, their participants had heterogeneous platforms and participants. In both cases, there were no formal centers of command, and their articulation was made possible by internet.
\end{abstract}

Key words: June journeys; urban social movements; passe livre movement; pt' government.

Este artigo analisa as manifestações que irromperam em centenas de cidades brasileiras em junho de 2013, inicialmente contra o aumento das passagens de transportes coletivos em São Paulo ${ }^{1}$.Considera-se que o caráter espontâneo dessas manifestações tem sido superestimado, em prejuízo da investigação sobre seus vínculos com movimentos social (MS) preexistentes, como o movimento Passe Livre (MPL), que convocou os primeiros protestos na capital paulista. Aparentemente, tratam-se de formas de ação coletiva díspares, a começar pela duração, alcance espacial e abrangência: os protestos duraram pouco mais de um mês, alcançaram quase todo o Brasil urbano, atraíram milhares de pessoas e deram expressão às pautas mais diversas. Já o MPL teve maior duração, menor amplitude espacial e pautas específicas. Os pontos de convergência, porém, devem ser destacados: os dois tipos de ação coletiva caracterizam-se pela horizontalidade, heterogeneidade de participantes e ausência de centros formais de comando, o que é viabilizado pelo uso da internet. Assume-se, aqui, o risco de incorrer em generalizações apressadas, pelo pouco tempo transcorrido desde junho de 2013. Acredita-se, entretanto, que a comparação entre ações coletivas consideradas em termos ideal-típicos lança luz sobre as formas do fazer político não institucionalizado, na nova conjuntura marcada pela hegemonia do Partido dos Trabalhadores (PT), desde o primeiro mandato do presidente Lula, iniciado em 2003.

\section{Aproximações conceituais}

O ponto de partida para a presente discussão é definir os fenômenos que serão considerados: “ciclos de protestos” e "movimentos sociais” (MS), 
subsumidos na categoria mais ampla “ação coletiva”. Outras categorias têm sido utilizadas pelos estudiosos (e.g. Gohn, 2011), mas são não necessárias para os fins do presente artigo. Consideram-se como "ciclos de protestos” mobilizações massivas, com formas variadas de expressão, com duração limitada (alguns dias ou semanas) e caracterizadas pela fluidez e informalidade (Burke, 2002). Correspondem à intensificação dos conflitos, à confrontação com oponentes e à incorporação acelerada de novos participantes (Bringel, 2011), que com frequência recorrem à ação direta, ignorando mediações institucionais. Marchas e ocupações, saques e quebraquebras reiterados são exemplos desse fenômeno.

Os MS são mais duradouros e articulados: seus participantes encontram-se com mais frequência, planejam ações e definem estratégias de longo ou pelo menos médio prazo. Os modos como os MS se organizam são variados: podem ser formais ou informais, hierárquicos ou horizontais. Dizer que um movimento social pode ser organizado não significa igualá-lo a uma organização institucionalizada, como sindicato ou associação de moradores. Tal distinção é crucial, pois organizações formalizadas podem ter um efeito paralisante, tornando-se burocráticas e sujeitas à cooptação (Burke, 2002; Gondim, 1991; Michels, 1984; Piven \& Cloward, 1979). A rejeição a organizações preexistentes frequentemente ocorre na fase inicial das mobilizações, como foi o caso do "novo sindicalismo" na região do ABC em São Paulo² nos anos 1970, que, liderado por Luiz Inácio da Silva (Lula), insurgiu-se contra a estrutura sindical existente (Sader, 1988).

Chama-se atenção que, como tipos ideais, as categorias “movimentos sociais" e "ciclos de protestos" têm valor heurístico, no sentido de direcionar o olhar do pesquisador para discernir, na realidade caótica dos fatos, aqueles que fazem sentido, a partir de suas variações em relação à tipologia previamente definida (Weber, 1991). É importante distinguir tipos de participantes, motivos, estratégias, formas de ação e possíveis consequências; tais distinções, porém, servem não para encaixar a realidade, mas para mostrar o quanto e como esta se aproxima ou se distancia dos modelos, podendo levar à reformulação das categorias.

A definição de movimentos sociais aqui formulada não tem como núcleo o seu impacto transformador da estrutura social. Essa visão teleológica, comum entre estudiosos (Alexander, 1998; Castells, 2011; Touraine, 1989), torna o objeto de pesquisa limitado às lutas bem sucedidas em seu objetivo de “mudança radical”. A dependência de avaliações expostdeixa os pesquisadores de MS desamparados em termos teóricometodológicos, já que a radicalidade das mudanças dependerá do ponto de vista do observador, pois não há critérios consensuais para identificar "mudança radical”. Para além de exemplos notórioscomo as revoluções francesa, russa e chinesa, mesmo MS que lograram transformarleis e práticas institucionais, como o movimento pelos direitos civis nos EUA, têm seu impacto contestado (Piven \& Cloward, 1979). O distanciamento histórico requerido para avaliações desse tipo torna a questãoparticularmente espinhosa quando se trata de analisar o alcance de mobilizações que 
emergiram no século XXI.O Occupy Wall Street é apontado como fracassado, porque os manifestantes foram retirados do espaço público sem obter nenhuma alteração no capitalismo financeiro; mas também é avaliado como exitoso, por ter fomentado a difusão de novos valores democráticos (Castells, 2013). Algumas mobilizações resultaram em mudanças políticas visíveis, como o movimento “Fora Collor” no Brasil, em 1992, o qual provocou o impeachment do presidente da República. Foi o caso, também, da "Primavera Árabe”, que logrou a derrubada de regimes ditatoriais. Supondo, para fins de argumentação, que esses e outros movimentos sociais tenham alcance restrito quando se trata de mudar a sociedade e a cultura, descartá-los como objeto de estudo empobreceria a compreensão da dinâmica política e das relações de poder na sociedade.

Rejeita-se, aqui, a visão reducionista que prevaleceu na década de 1970, a qual considerava os MS como um subproduto das contradições do capitalismo, reduzindo os sujeitos sociais à condição de "atores-suportes" (Castells, 2011:376). A perspectiva adotada é que estrutura e ação são componentes da realidade social, que se expressa tanto nas práticas simbólicas, como nas condições materiais de produção e reprodução. Nessa perspectiva, consideram-se os movimentos sociais comoprocessos que ecoam e produzem mudanças - não necessariamente radicais - no contexto político, nas condições socioeconômicas e nos modelos culturais.

A gênese dos movimentos sociais e de protestos massivos deve ser buscada não apenas em suas manifestações públicas, mas no seu interior, nas relações entre seus participantes, em suas visões de mundoe em suas interpretações dos acontecimentos (Zibechi, 2013).As práticas para mudar a realidade material se associam a um trabalho de constituição de significados, mediante a produção de "framesde ação coletiva”: quadros interpretativos formulados a partir de "conjuntos de crenças e significados orientados para a ação que inspiram e legitimam as atividades e campanhas da organização de um movimento social” (Benford, Snow 2000: 614). Esse conceito de frame de ação coletiva, inspirado em Goffman (1974), destaca o aspecto cultural dos MS, na medida em que os quadros interpretativossimplificam e condensam aspectos do mundo exterior, no sentido de mobilizar apoiadores potenciais e "desmobilizar antagonistas" (Benford; Snow 2000:614).

\section{Movimentos sociais e ciclos de protestos: visibilidade e invisibilidade}

A hipótese deste artigo é que as jornadas de junho de 2013 não surgiram de repente, nem foram tão espontâneas quanto indica o slogan“o Brasil despertou”, usado recorrentemente pelos manifestantes. Considera-se equivocada a descrição do panorama político brasileiro anterior aos protestos como um campo sem fissuras onde o grupopolítico hegemônico, comandado pelo Partido dos Trabalhadores (PT), teria fabricado um consenso. 
Foram surpreendentes, de fato, a rápida massificação e a disseminação das manifestações pelas cidades brasileiras, com sua horizontalidade, heterogeneidade e ausência de centros decisórios, substituídos por articulações via internet. Mas desde o primeiro governo Lula havia protestos de ruas ou MS com um perfil diverso daqueles existentes na época da formação do PT (Zibechi, 2013). Os que usam a metáfora do terremoto para caracterizar os protestos de junho parecem ignorar que tremores de terra não ocorrem sem o prévio deslocamento de placas tectônicas: a invisibilidade de um fenômeno não equivale à sua inexistência.

A surpresa dos analistas em relação à irrupção de ações coletivas tem sido recorrente. Tal surpresa decorredas lentes teóricas de pesquisadores, as quais acentuam, ao invés de corrigir, sua miopia em relação aos processos menos visíveis. Na raiz destes, encontra-se um fator difuso, a indignação - um estado de ânimo decorrente da transformação do medo ou da apatia em raiva e a canalização desta para a revolta contra injustiças (Bringel,2013; Castells, 2013). A indignação tem formas diversas de se expressar, indo desde atos individuais e por vezes desesperados (como a imolação de monges budistas contra a guerra do Vietnã), a ações de massa violentas, pontuais (quebra-quebras, invasões e destruição de propriedades) ou mais ou menos continuadas (MS, ciclos de protestos ou revoluções). As raízes do sentimento por trás desses processos devem ser buscadas nas transformações ocorridas na estrutura social e na conjuntura política.

A experiência histórica deveria nos acautelar contra diagnósticos pessimistas que afirmam a apatia dos jovens ou da classe trabalhadora e a fragilidade das contestações à ordem vigente. Assim, entre as décadas de 1930 e 1960, na Europa e nos EUA, teorias sobre a desmobilização política, cujo tom pessimista ecoava os avanços de regimes totalitários, tomaram o lugar das discussões sobre revoluções. (Alonso, 2009). A argumentação apontava a desmobilização política como fruto de um individualismo exacerbado, produzido pela sociedade de massa. Contudo, a década de 1960 foi de grande efervescência contestatória, cujos protagonistas não eram nem o proletariado, nem multidões com comportamento irracional e sem objetivos claros. Na Europa e nos Estados Unidos, os novos sujeitos não se identificavam pela pertença a uma classe social, ainda que majoritariamente se situassem em estratos médios da sociedade (estudantes, profissionais liberais, artistas e outros). Suas demandas não expressavam interesses materiais, nem reivindicações pelo acesso ao poder estatal. O que reivindicavam, por meio de ação externa a organizações convencionais (sindicatos, partidos, associações institucionalizadas etc.), eram mudanças nas formas de vida - rejeição ao consumismo, respeito ao meio ambiente, reconhecimento dos direitos de grupos subordinados, como mulheres, negros e homossexuais.

As décadas de 1960 e 1970 foram momentos de intensa mobilização também na América Latina, malgrado a repressão exercida por regimes autoritários. Durante a ditadura instaurada no Brasil em 1964, predominava entre os estudiosos a visão de que os trabalhadores eram subordinados 
aos ditames do Estado e da acumulação de capital, alienados e massificados pela mídia. Essas representações só foram reconhecidas como inadequadas quando irromperam greves fomentadas pelo "novo sindicalismo” na região do ABC paulistae MS clamando por habitação, saneamento básico, creches, escolas, postos de saúde etc. (Sader, 1988). Dessas mobilizações nasceria, sob a liderança do metalúrgico Lula, o PT, em 1980.

A sociologia demorou um pouco a explicar esses MS, cujas origens estavam relacionadas a práticas pouco visíveis, que se davam na esfera do cotidiano. No contexto do autoritarismo, tratava-se de um fenômeno novo, cuja própria percepção demandava a formulação de novas categorias e novos métodos de investigação nas Ciências Sociais (Sader, 1988), capazes de compreender os novos “quadros interpretativos” dos MS.

Outro marco da década de 1980 foi o ciclo de mobilizações reivindicando eleições diretas para presidente da República. Essa reivindicação levou às ruas uma massa heterogênea de muitos milhares de pessoas, com a presença de partidos de oposição, sindicatos, associações profissionais e MS. Ainda que não tenha sido aprovada a emenda constitucional que reestabelecia eleições diretas, o Congresso elegeu, indiretamente, o candidato não apoiado pelos militares, Tancredo Neves. Este morreu antes de assumir a presidência, que foi ocupada pelo vice-presidente José Sarney, político conservador. Em 1986, o então presidente adquiriu grande popularidade devido ao sucesso momentâneo do Plano Cruzado no combate à inflação. Sucederam-se outros planos econômicos, igualmente fracassados. Essa foi uma época de grande mobilização política, relacionada aos trabalhos da Assembleia Nacional Constituinte, iniciados em 1987, com intensa participação tanto de lobbies conservadores, como de MS.

A Constituição de 1988 trouxe muitos avanços para os direitos de cidadania, inclusive a criação de espaços para políticas públicas participativas. Paradoxalmente, esses avanços coincidiram com perdas econômicas decorrentes de uma crise e da subsequente ascensão do neoliberalismo, na década de 1990. Na mesma época, diminuíram os embates provocados pelos MS, o que foi identificado como enfraquecimento ou mesmo fracasso. Tal avaliação, entretanto, descarta a relevância da atuação de redes e articulações sociais, Organizações Não Governamentais e outros atores, como universidades e centros de pesquisa, no sentido de fortalecer demandas ao Estado por políticas públicas e efetivação de direitos (Bringel, 2013). Por um lado, a adoção de mecanismos de participação por governos locais de esquerda, inclusive do PT (fóruns, conselhos, orçamento participativo etc.), incentivou os atores de MS a buscarem capacitação técnica e político-institucional com a colaboração de ONGs, assessorias populares, associações profissionais, universidades etc. Por outro lado, o retorno dos mecanismos da democracia representativa (partidos, inclusive de esquerda, competindo em eleições e por maiorias parlamentares) alimentou práticas clientelistas, por vezes exercidas por lideranças provenientes de MS, atuando como "cabos eleitorais" ou buscando cargos no Legislativo ou Executivo. Outras características do contexto social dos anos 1990 
também tiveram um impacto amortecedor nos MS: a expansão das igrejas evangélicas, com perfil conservador, e a presença de traficantes de drogas ou milícias, que muitas vezes passaram a exercer um poder despótico sobre moradores de comunidades pobres, particularmente no Rio de Janeiro.

O perfil menos aguerrido dos MS nessa década deveu-se também à dificuldade de manter altos níveis de ativismo por longos períodos de tempo, quando não há ameaças imediatas, ou em seguida a vitórias, mesmo pontuais (Santos, 1981). De um modo geral, o próprio sucesso dos movimentos tende a estimular a formação de organizações burocratizadas, que contêm o ímpeto da contestação inicial, como foi mencionado. A experiência histórica mostra que, malgrado essa tendência, ações coletivas e manifestações de massa ressurgem: pode-se dizer que alternam períodos de latência e visibilidade (Merlucci, 1989), os quais se retroalimentam. Durante a latência, os sujeitos sociais articulam-se, elaboram e vivenciam novos códigos culturais, criam laços de solidariedade e seguem cursos de ação que os tornam visíveis. Por sua vez, a visibilidade "fornece energia para renovar a solidariedade, facilita a criação de novos grupos ou o recrutamento de novos militantes atraídos pela mobilização pública que então flui na rede submersa” (Melucci, 1989:62).

No Brasil, a década de 1990 parece ter sido um momento de "hibernação", mas não de paralisação, para os MS. O ímpeto já não era o mesmo dos anos 1970 e 1980, inclusive porque o quadro político-institucional estimulou novos canais de representação popular, como foi dito. Ao mesmo tempo, prevalecia a repressão aos MS no âmbito da política nacional, controlada pela política neoliberal, representada pelo Presidente Fernando Henrique Cardoso, do Partido da Social-Democracia Brasileira (PSDB).

Contudo, ações de maior visibilidade persistiram, como o Movimento dos Sem Terra (MST), que se consolidou em nível nacional e continuou promovendo marchas e ocupações (Campos, 2014). Outros grupos manifestavam-se por direitos sociais ou contra perdas salariais: greves de funcionários públicos e de professores universitários; ação direta, como ocupações de terras urbanas por famílias sem acesso à habitação digna; marchas pela demarcação de terras indígenas; e eventos onde o protesto combinava-se a uma dimensão festiva, como as Paradas Gay. Assim, os MS não saíram propriamente da cena pública, mas novas categorias de análise, como "sociedade civil” e "esfera pública” passaram a prevalecer nas pesquisas sobre cultura política. (Lavalle, Castello, Bichir, 2004).

\section{Transformações no contexto político-institucional brasileiro nas últimas décadas}

A década de 1980 encerrou-se com a derrota do projeto do PT para assegurar os direitos sociais reivindicados pelos MS e prometidos pela Constituição de 1988. Na primeira eleição presidencial direta, em 1989, Lula foi derrotado por Fernando Collor, cuja principal bandeira era a promessa 
demagógica de moralizar o Estado e a política. Ironicamente, o presidente eleito foi acusado de uso de recursos públicos em benefício próprio, o que motivou o seu impeachment em 1992. Essa medida foi precedida por amplas manifestações, protagonizadas principalmente por jovens, os “carapintadas", assim chamados em alusão à pintura de seus rostos em verde e amarelo (as cores da bandeira nacional). $\mathrm{O}$ vice-presidente Itamar Franco assumiu o restante do mandato, quando foi elaborado o Plano Real, associado ao então Ministro da Fazenda, Fernando Henrique Cardoso. Este, como candidato do PSDB, derrotou Lula nas eleições de 1994, em grande medida devido ao sucesso daquele plano de estabilização financeira. Nova vitória ocorreu em 1998, o que significou oito anos de hegemonia de um projeto neoliberal que promoveu privatizações de toda ordem e reprimiu greves e MS. A inflação foi controlada, mas a economia estagnou e o desemprego permaneceu alto.

A eleição do candidato petista em 2002 viabilizou um novo projeto político e social para o Brasil. Ainda que não tenham modificado a política monetária anterior, Lula e sua sucessora, Dilma Rousseff, levaram a efeito políticas sociais que melhoraram significativamente as condições de vida dos pobres e da classe média baixa, retirando milhões de pessoas da miséria: Bolsa-Família (complementação de renda familiar), Programa de Fortalecimento da Agricultura Familiar e o Programa Luz para Todos, por exemplo. O salário-mínimo aumentou a níveis mais altos que a inflação, tornou-se mais fácil obter crédito e o emprego no setor formal expandiu-se, propiciando maior acesso a bens de consumo e fortalecendo o mercado interno. Ressalve-se que os 17 milhões de empregos criados entre 2004 e 2012 são, em sua maioria, de baixa qualidade: em 80\% deles, a remuneração é, no máximo, de dois salários mínimos, e a rotatividade é intensa: “as pessoas são contratadas, ficam na ocupação por menos de um ano e são substituídas por outras” (Cardoso, 2013: 28).

Os governos do PT investiram em grandes obras de infraestrutura, sobretudo no segundo mandato de Lula, iniciado em 2007, quando foi lançado o Programa de Crescimento Acelerado (PAC). Para fazer frente à crise mundial de 2008, o PAC II e o Programa Minha Casa, Minha Vida foram elaborados para “aquecer" a economia, favorecendo os setores imobiliário e da construção civil. Tal modelo aumentou o emprego (precarizado) na construção civil, mas também inflacionou os preços dos imóveis. O financiamento massivo para a produção imobiliária fez com que piorasse a já desordenada ocupação do espaço urbano (Maricato, 2013). Surgiram novos bairros de classe média e conjuntos habitacionais de baixa renda, em geral de baixa qualidade e sem obedecer a diretrizes de planejamento urbano. Grande parte da população pobre tem sido expulsa para periferias sem condições adequadas de saneamento básico, iluminação pública, transportes etc. Âqueles sem acesso ao mercado formal de habitação resta a alternativa de ocupar os terrenos que "sobram", sem saneamento básico e sujeitas a riscos de inundações e deslizamentos, muitas vezes em áreas de preservação permanente. 
A qualidade de vida não depende apenas de bons salários, mas também da provisão de bens e serviços cujo acesso deve ser universal, como educação e saúde. No Brasil, nenhum governo conseguiu assegurar a qualidade desses serviços, o que tem levado ao incremento da demanda por aqueles ofertados pelo setor privado, com o consequente endividamento das famílias. Nas cidades, a situação se complica porque a urbanidade depende dos chamados bens de consumo coletivo (habitação popular, saneamento básico, iluminação pública, segurança, transportes etc.), cuja oferta cabe principalmente a Estados e Municípios, diretamente ou por meio de concessões a empresas privadas. O governo federal é importante parceiro dos outros níveis de governo, pois dispõe de mais recursos para financiamento.

Nesse contexto, sobressai a questão da mobilidade urbana, motivação inicial dos protestos de junho de 2013. Os usuários de transportes públicos, caros e de má qualidade, têm sido particularmente prejudicados. Salvador, Recife e Fortaleza,principais metrópoles situadas na Região Nordeste a mais pobre do País -sequer têm sistemas de transporte de massa, apesar de terem população superior a 2,5 milhões de habitantes cada. Em todas as regiões metropolitanas, a proporção de deslocamentos casa-trabalho com duração superior a uma hora (considerando somente o trajeto de ida) aumentou, sobretudo a partir de meados da década de 2000. No Rio de Janeiro e em São Paulo, o percentual desses deslocamentos é superior a $20 \%$ do total. Mesmo em Curitiba e Porto Alegre, que têm sistemas de transporte mais eficientes, a situação não melhorou, pois a proporção de longos deslocamentos permaneceu constante no período de 1992 a 2009. (Pereira \& Schwagen, 2014). Essa situação reflete o aumento considerável da frota de automóveis, cujo incremento entre 2001 e 2011chegou a quase $80 \%$ nas metrópoles brasileiras - um acréscimo de 8,9 milhões de automóveis na década, ou, em média, mais de 890 mil veículos por ano. (Rodrigues, 2012). Para tanto contribuiu a prioridade conferida pelo governo ao transporte individual, mediante isenção fiscal para aquisição de automóveis e o financiamento, no âmbito do PAC, da construção de obras de infraestrutura viária: viadutos, túneis, ampliação de avenidas etc. (Maricato, 2013).

Paradoxalmente, a questão urbana agravou-se durante os governos de um partido que nasceu comprometido com o Movimento Nacional pela Reforma Urbana (MNRU). O governo Lula promoveu grandes avanços institucionais, como a criação do Ministério das Cidades (MC) e programas de capacitação e financiamento para a elaboração, pelos governos locais, de planos diretores participativos. Estes adotaram (mas não efetivaram) instrumentos destinados ao ordenamento do uso e da ocupação do solo urbano, estabelecidos no Estatuto das Cidades, aprovado em 2001 (Santos Jr.\& Montandon, 2011).

A atuação do MC começou a ser minada com a substituição do Ministro Olivio Dutra - político petista historicamente ligado com o MNRU - por Marcio Fortes, indicado por um partido conservador, na reforma ministerial efetivada pelo presidente Lula para enfrentar a crise política 
decorrente do escândalo do "mensalão" (esquema comandado pelo ministro petista José Dirceu que, supostamente, fazia pagamentos mensais a deputados para votarem a favor de projetos do governo). A substituição de Olívio Dutra é emblemática da adesão do governo petista ao modelo "pemedebista” ${ }^{3}$ (Nobre, 2013), baseado na construção de alianças com representantes de forças políticas díspares, a fim de garantir ampla maioria suprapartidária no legislativo, em troca de cargos e benesses. Esse pacto cobrou seu preço em tolerância ou mesmo apoio à corrupção: políticos de direita, como os senadores Sarney e Renan Calheiros, com o apoio do presidente Lula, não só saíram ilesos de acusações de corrupção, como foram conduzidos à presidência das Casas Legislativas.

Malgrado a corrosão de seus princípios éticos e ideológicos, o PT logrou amplo apoio popular, devido a políticas sociais mais equitativas, o que lhe garantiu sucessivas vitórias eleitorais, principalmente na região Nordeste, que concentra o maior número de beneficiários do Bolsa Família. No pleito de 2010, mais uma vez, venceu a candidata do PT, Dilma Rousseff, que deu continuidade ao modelo desenvolvimentista, aliado à expansão das políticas sociais. Apesar do perfil mais tecnocrático, a nova presidente aderiu ao "pemedebismo", fazendo concessões a aliados de diversos partidos, a fim de garantir a vitória de projetos governamentais ou evitar crises políticas que poderiam decorrer de denúncias de corrupção ${ }^{4}$.

Até junho de 2013, os críticos à esquerda e à direita do PT pareciam subjugados na esfera institucional, porém setores da sociedade civil usavam outros canais de oposição. A mídia escrita e televisiva, controlada por oligopólios, passou a fazer críticas insistentes ao governo federal, dando ampla cobertura a denúncias de corrupção. O julgamento dos acusados do "mensalão" e sua condenação pelo Supremo Tribunal Federal, com base em argumentos jurídicos discutíveis, tornou-se um espetáculo midiático. A oposição à esquerda, por sua vez, permanecia criticando - sem grande repercussão - as alianças espúrias do PT, as consequências ambientais e urbanísticas das políticas desenvolvimentistas e o afastamento, quando não antagonismo, do governo em relação aos MS.

Olhando-se as práticas políticas visíveis na sociedade e nas instituições políticas em 2013, era tentador afirmar que o país "parecia viver uma espécie de vertigem de prosperidade e paz” (Rolnik, 2013, s/p.). Dentre os MS surgidos antes da era Lula, o MST era provavelmente o único que subsistia com postura crítica em relação ao governo e com visibilidade na mídia (Campos, 2014). Alguns movimentos urbanos ocasionalmente promoviam ações públicas intermitentes, como nos casos do Movimento dos Trabalhadores Sem Teto, Central de Lutas Populares e Movimento Nacional de Luta pela Moradia. Nos interstícios desse tecido social formavam-se redes entre ONGs, coletivos e comitês com perfil heterogêneo, com militantes ligadosao Psol, PSTU, sem filiação partidária ou anarquistas.

O primeiro movimento de âmbito nacional a se articular nos governos do PT foi o Movimento pelo Passe Livre (MPL) (Romão, 2013). O foco no 
transporte público evidencia a importância desse serviço para a vida urbana, para a qual os deslocamentos frequentes são condição sine qua non, com destaque para as viagens casa-trabalho. Não por acaso, movimentos contra aumentos de tarifas e má qualidade dos transportes têm sido recorrentes ao longo da história do Brasil: desde a Revolta do Vintém no Rio de Janeiro em 1879, às depredações de bondes e ônibus nesta e em outras cidades ao longo do século XX (Pessoa, 2014). Em 1975, em plena ditadura militar, a duração e intensidade de quebra-quebras de trens suburbanos no Rio de Janeiro e em São Paulo fizeram com que estudiosos enxergassem neles um potencial transformador, a exemplo dos MS que então ressurgiam (Moisés; Martinez-Allier, 1978).

Na década de 2000, ocorreram manifestações em várias cidades brasileiras contra o aumento das tarifas de ônibus. A primeira delas, em 2003, foi a "Revolta do Buzu” (corruptela da palavra ônibus) em Salvador, que durou cinco semanas e reuniu milhares de estudantes universitários e secundaristas, muitos pertencentes a famílias de trabalhadores pobres (Zibechi, 2013). Em dez anos, ocorreram outros movimentos desse tipo: “revoltas da Catraca” em Florianópolis (2004 e 2005); mobilizações em Vitória (2005), Brasília (2009), São Paulo (2009, 2011), Teresina (2011) e Porto Alegre (abril de 2013) (Movimento Passe Livre, 2013). Por trás dessa face visível, foram criados comitês e coletivos que, durante o V Fórum Mundial de Porto Alegre, em 2005, fundaram o MPL.

A Carta de Princípios do MPL o define como "um movimento horizontal, autônomo, independente e apartidário, mas não antipartidário. A independência do MPL se faz não somente em relação a partidos, mas também a ONGs, instituições religiosas, financeiras etc. [...] A via parlamentar não deve ser o sustentáculo do MPL, ao contrário, a força deve vir das ruas." Seu foco é a transformação radical do sistema de transporte coletivo vigente, "retirando-o da iniciativa privada, sem indenização, colocando-o sob o controle dos trabalhadores e da população”. (Carta de Princípios do Movimento Passe Livre, 2007, s/p). O êxito do MPL em desencadear manifestações massivas em várias ocasiões parece indicar a aceitação do “quadro interpretativo” centrado na questão da mobilidade urbana e traduzido numa reivindicação pontual (contra o aumento das tarifas), mas com poder de aglutinação de pautas mais amplas: “crescimento desordenado das metrópoles, relação cidade e meio ambiente, especulação imobiliária e a relação entre drogas, violência e desigualdade social [...] defesa da liberdade de manifestação, contra a repressão e criminalização dos movimentos sociais”. (ibid.).

Outro movimento social relevante para as jornadas de junho foram os Comitês Populares da Copa, integrados por movimentos sociais, Ongs, intelectuais, estudantes e moradores de comunidades pobres, organizados nas cidades que sediariam grandes eventos, especialmente a Copa das Confederações de 2013 (Rio de Janeiro, Belo Horizonte, Brasília, Salvador, Recife e Fortaleza), a Copa do Mundo de 2014 (mesmas cidades e também Porto Alegre, São Paulo, Curitiba, Goiânia, Manaus e Natal) e as Olimpíadas 
de 2016 (Rio de Janeiro). A articulação desses comitês ocorreu durante o Fórum Social Urbano de 2011, quando se formou uma rede nacional, com representantes das cidades onde ocorreriam megaeventos. Tanto quando no MPL, prevaleceu uma organização horizontal, sem lideranças formais e com intensa articulação pela internet.

A Articulação Nacional dos Comitês Populares da Copa publicou documentos e promoveu eventos acadêmicos e manifestações, denunciando a falta de transparência das ações do Poder Público relativas a planos, projetos, orçamentos e contratos relacionados aos megaeventos; o desperdício de recursos públicos com obras de prioridade discutível, com reformas ou construção de novos estádios; o desrespeito aos direitos trabalhistas nas obras contratadas. Uma das violações de direitos humanos enfatizada eram os despejos e remoções de comunidades pobres para dar lugar a obras de infraestrutura viária ou para a construção de equipamentos esportivos. (Articulação Nacional dos Comitês Populares da Copa, 2012).

Outro ponto muito criticado eram os privilégios concedidos à Fédération Internationale de Football Association (FIFA) pelo governo brasileiro por meio da Lei Geral da Copa, aprovada em maio de 2012. Por exemplo, a venda de alimentos, bebidas e outras mercadorias nos locais dos jogos, em sua vizinhança e nas principais vias de acesso dependeria de permissão daquela entidade privada e internacional, à qual foi concedido, também, o poder de determinar os preços dos ingressos e de controlar sua venda. Um dos motivos de maior indignação contra a lei da Copa era a permissão para a interferência da FIFA na soberania nacional, chegando ao ponto de alterar a própria legislação do País. Exemplos disto eram a permissão para criar juizados especiais e varas para decidir sobre demandas relativas aos jogos, e a concessão de vistos de entrada e permissões de trabalho a qualquer pessoa indicada pela FIFA, dentre seus parceiros comerciais e indivíduos portadores de ingressos para os jogos. (Articulação Nacional dos Comitês Populares da Copa, 2012).

\section{3 de junho de 2013}

As manifestações de junho de 2013 foram um evento inédito na história do País. Em número de participantes, só têm paralelo com a campanha por eleições diretas e o movimento "Fora Collor", mas ambos eram direcionados para um único e amplo objetivo e sua organização contou com a presença de partidos políticos e outros setores organizados, como associações profissionais, ONGs e MS. Outro aspecto peculiar às Jornadas de Junho é que não foram um único evento, devido tanto às especificidades que assumiram em diferentes cidades, como a modificações ocorridas ao longo do período em que duraram os protestos.

Recapitulando: as manifestações lideradas pelo MPL começaram em São Paulo, depois do anúncio do aumento de $\mathrm{R} \$ 3,00$ para $\mathrm{R} \$ 3,20$ nas tarifas de ônibus e de metrô, de responsabilidade, respectivamente, do 
governo municipal (PT) e do governo estadual (PSDB). Os primeiros atos públicos, realizados nos dias 3, 7 e 11 de junho, atraíram relativamente poucas pessoas, em geral estudantes, e não despertaram a atenção da mídia nacional. O protesto realizado no dia 13, entretanto, teve grande repercussão, devido à violência com que a polícia reprimiu o ato, atingindo, inclusive, vários profissionais da imprensa. A partir daí, as manifestações começaram a se multiplicar, ramificando-se por centenas de cidades nos 27 Estados do Brasil e atraindo milhares de pessoas.

Em São Paulo, o quinto ato, programado para o dia 17 de junho, foi avaliado por um jornalista como uma "metamanifestação": a violência com que a polícia reprimiu o ato anterior fez com que as pessoas se manifestassem pelo direito de protestar nas ruas, e transformou o movimento em um "poderoso imã de manifestações” (Knijnik; Lima; Ortellado, 2013, p. 154).

A essa altura, o aumento das tarifas tornou-se apenas uma entre múltiplas pautas, como diziam os cartazes: "não é apenas por 20 centavos". Denunciavam-se o cerceamento à liberdade de expressão, a insuficiência de recursos para educação e saúde, a corrupção e os elevados recursos públicos destinados a grandes eventos esportivos ("queremos educação padrão FIFA”). Um fato era notório: os manifestantes criticavam mais a política,em geral, do quepolíticos em particular.

Temas mais específicos também eram destacados, como a presença de um pastor evangélico homofóbico na Comissão de Direitos Humanos da Câmara dos Deputados, e a proposta de emenda constitucional para retirar o Ministério Público de investigações policiais (PEC 37), o que dificultaria a apuração de denúncias de corrupção e violações de direitos humanos. Em suma, foi “um momento epifânio de explosão de muitas pautas” (Vitagliano, 2013).

Um ponto a destacar é que não houve centros decisórios nem no início, nem durante as manifestações. A informalidade dos protestos ficou evidente na ausência de carros de som, no caráter artesanal dos cartazes e nas poucas faixas que se destacavam. Quem se manifestou não o fez atendendo ao chamado de partidos políticos, sindicatos ou associações de bairro; a divulgação dos protestos foi feita por meio das redes sociais, à semelhança de outros movimentos, como os Indignados na Espanha ou o Occupy Wall Street nos EUA ${ }^{5}$.O próprio percurso das marchas não seguia um direcionamento único e os participantes se dividiam quanto ao uso de táticas violentas para responder à violência da polícia.

O acirramento da repressão não é específico ao Brasil, nem é um fenômeno inédito no tratamento dado aos MS pelo braço armado do Estado (Bringel, 2013). No entanto, no século XXI a criminalização dos protestos tem assumido novos contornos a partir dos atentados de 11 de setembro de 2001, quando atos terroristas de movimentos fundamentalistas ganharam maior visibilidade e passaram a ser usados para justificar leis de exceção. Antes apanágio de ditaduras, essas leis começam a se tornar regra em Esta- 
dos ditos democráticos, como é o caso do Ato Patriótico nos Estados Unidos. Na Europa, em abril de 2010 o Conselho Europeu de Assuntos Gerais aprovou o Documento 8570/10, que prevê a vigilância de pessoas com comportamento radical, sejam de direita ou de esquerda, nacionalistas ou antiglobalização (Bringel, 2011). No caso dos protestos de junho no Brasil, a violência não se fez sentir apenas pela ação direta de policiais durante os protestos, mas também pelas posturas do sistema judiciário: houve prisões arbitrárias e cerceamento do direito à defesa, com impedimento ou restrições do acesso de advogados aos acusados de "vandalismo".

Nos confrontos ocorridos nas ruas, a polícia usava balas de borracha, gás lacrimogêneo, agressões físicas a manifestantes e a profissionais da imprensa, indiscriminadamente, sobretudo nas proximidades de parlamentos e sedes de governos, e no entorno dos estádios onde se realizavam jogos da Copa das Confederações. A reação violenta dos manifestantes passou a ser uma constante, com o uso de pedras, garrafas e rojões, construindo barricadas com lixo e pedaços de madeira, danificando estabelecimentos bancários ou comerciais,destruindo o mobiliário urbano eincendiando veículos.

Pelas próprias características do movimento, as atitudes com relação ao uso da violência diferiam: para muitos, tratava-se de uma resposta necessária à truculência policial; outros eram contrários a qualquer ato dessa natureza. Alguns grupos, dos quais o mais visível eram os Black Blocs, colocaram-se publicamente a favor de tomar a iniciativa do ataque. Registraram-se, ainda, casos de agentes das próprias forças de segurança infiltrados, bem como a realização de saques por oportunistas, nem sempre reprimidos pela polícia. A grande mídia tendia a ignorar a complexidade da situação, insistindo numa postura maniqueísta que dividia os manifestantes entre "pacíficos” ou "vândalos”.

Segundo pesquisa realizada no dia 21 de junho com uma amostra de manifestantes em oito capitais (Fantástico, 2013), a maioria dos participantes era constituída por jovens (63\%), dos quais 43\% tinham menos de 25 anos, ou seja, eram crianças ou não haviam sequer nascido quando ocorreu o último ciclo de protestos massivos no Brasil, o “fora Collor” em 1992. Se em junho de 2013 muitos participavam de manifestações pela primeira vez, os 19\% com mais de 40 anos provavelmente tinham experiência ou pelo menos memórias de protestos anteriores.

A diversidade profissional e socioeconômica, apontada pela mesma pesquisa (Fantástico, 2013),indica que não se tratavam de eventos predominantemente de classe média, nem tipicamente estudantis. Ainda que o número de estudantes correspondesse a 52\%, a grande maioria (76\%) dos manifestantes trabalhava (neste percentual estão incluídos aqueles que trabalhavam e estudavam, e os que só trabalhavam). Quanto à renda familiar, 56\% situavam-se no estrato entre 2 e 10 salários mínimos (o salário mínimo da época era de 678 reais, correspondendo a cerca de 300 dólares), havendo participantes no estrato superior (26\% ganhavam mais de 10 
salários mínimos) e inferior (15\% ganhavam menos de dois salários mínimos). O perfil heterogêneo é consistente com a participação de moradores de periferias e favelas - jovens, adultos e idosos, muitos dos quais negros - que conhecem a violência policial em seu cotidiano. Que essa questão tenha sido tematizada nas ruas tornou visível para a classe média "a brutalidade policial, que os pobres e negros nunca ignoraram” (Soares, 2013).

A rejeição à política institucional e à corrupção, muitas vezes associada à exaltação de valores nacionalistas, eram temas de identidade ideológica evasiva, adotados tanto por aqueles que não conseguiam expressar sua indignação de forma mais específica ("todos unidos por um Brasil melhor"), como por pessoas conservadoras. A direita, que não mostrava sua cara nas ruas desde a Marcha da Família com Deus pela Liberdade, pouco antes do golpe de 1964, "pegou carona”, por assim dizer, nos protestos de junho de 2013. De um modo geral, estes transbordaram para a sociedade, ultrapassando as intenções e as motivações dos grupos que os iniciaram (Bringel, 2013).

Esse transbordamento foi favorecido pela existência de um descontentamento difuso, que até então não tinha encontrado canais para se transformar em revolta. O descrédito nos Poderes constituídos e nos mecanismos de representação (parlamentos, partidos, sindicatos, associações etc.), que aparentemente provocava apatia ou aceitação do status quo, transformou-se em indignação, uma vez divisada uma janela que, afinal, escancarou-se para todos os descontentes. Note-se que os sentimentos morais são constitutivos da ação coletiva: "toda mobilização coletiva é pontuada por experiências de indignação e revolta, solidariedade ou debandada, alegria ou decepção - a própria apatia não existe sem pathos" (Cefaï, 2009, p. 31).As jornadas de junho tiveram a peculiaridade de reunir nas ruas, pela primeira vez, setores de esquerda, de direita e indefinidos, com a convicção comum que os canais institucionais não serviam para expressar a revolta.

Alguns analistas identificaram no repúdio às instituições da democracia representativa tendências autoritárias, quando não fascistas (e.g. Santos, 2013; Chauí, 2013). Para Santos (2013), os manifestantes endossaram a visão conservadora disseminada na grande mídia, que atribui a falta de legitimidade dos partidos e dos políticos a condutas individuais moralmente condenáveis, ao invés de denunciar o sistema político que favorece tais práticas - que também vicejam na sociedade. Entretanto, a "crise de representatividade” não é uma criação da mídia nem da direita. Trata-se de uma situação real, decorrente, em grande parte, da transformação dos partidos em amálgamas de interesses, prontos para coligações sem consistência ideológica, motivadas pela busca ou manutenção do poder. Essa situação, que também se verifica em países europeus (Romão, 2013), é agravada pelo fato de que em todas as democracias vigentes, as eleições se transformaram em espetáculos midiáticos e atraem cada vez menos cidadãos, como indicam as altas taxas de abstenção. No Brasil, essa situação é exacerbada pela 
persistência do “pemedebismo”, já mencionada, em governos encabeçados por um partido que propugnava a ética na política.

A mídia alternativacumpriu um papel crucial para promover adesões massivas às manifestações, geralmente convocadas pelas redes sociais. $\mathrm{O}$ uso de celulares e a realização de vídeos in loco possibilitou o registro de cenas não divulgadas pela imprensa escrita e televisiva. Entretanto, a comunicação mediada por computador (CMC) não deve ser superestimada, pois seu papel foi potencializar, e não criar mobilizações, como se fosse um deus ex maquina.É um exagero identificar nessa mídia uma “cultura da autonomia” (Castells, 2013: 167) e considerá-la como uma superação da mídia convencional. Esta é, frequentemente, controlada por monopólios organizados verticalmente, acusados de parciais e manipuladores. Por sua vez, a CMC também é controlada por corporações lucrativas, como a Microsoft e a Apple, e utilizada pelas grandes empresas de comunicação. Os usuários não empresariais ou institucionais não detêm o controle técnico e econômico da mídia digital, à semelhança do que ocorre com o público dos meios de comunicação massivos (Chauí, 2013). Pela sua rapidez e flexibilidade, a CMC pode ser utilizada para os mais diversos fins: ouvir música enquanto se lê ou se verificam as mensagens do correio eletrônico; ler um texto acadêmico, interromper brevemente sua leitura para postar um comentário numa rede social, compartilhar uma foto, um fato ou uma anedota. O conteúdo assim produzido ou compartilhado pode ser o mais variado: um show de rock, mensagens entre amigos, abaixo-assinados ou convite para um evento político ou recreativo, por exemplo. Isso não significa, necessariamente, democratização da cultura ou da política, pois a quantidade de informações não é equivalente à qualidade. A CMC multiplicou exponencialmente a divulgação de trivialidades, dados inverídicos e pornografia, bem como a invasão da vida privada e a espionagem para fins políticos e econômicos. Sem falar que a internet pode ser usada indiscriminadamente para favorecer todo tipo de interesses e grupos, inclusive os adeptos de práticas autoritárias, como os neonazistas. Em suma, é um fato óbvio, mas por vezes ignorado, que a possibilidade de livre acesso a uma rede de comunicação não significa que ela será usada para fins políticos emancipatórios.

Não se quer, aqui, subestimar o impacto transformador da CMC na política, em particular nos MS. Seu alcance pode ser mais bem aquilatado se o uso da Internet e das redes sociais for considerado como um "repertório de ação” dos movimentos sociais, no sentido que Tilly dá ao termo:trata-se de um "[...] conjunto limitado, familiar e historicamente criado ${ }^{6}$ de meios à disposição das pessoas engajadas em confrontos políticos (Tilly, 2006:vii). O repertório abre espaço para a adoção de recursos variados no decorrer das interações, à semelhança de uma performance de jazz, onde o improviso está presente, mas as variações não são ilimitadas. Exemplificando, as manifestações que têm ocorrido na Europa e nos Estados Unidos ocuparam ruas, praça e parques, fizeram denúncias e comunicados à imprensa, mas evitaram bombardeios, sequestros e autoimolação (Tilly, 2008:14).Caberia acrescentar o uso massivo das redes sociais e da internet como elementos- 
chave do repertório dos movimentos sociais contemporâneos, combinado com as outras formas de protesto.A internet permite o livre acesso e a articulação de um enorme número de pessoas, de forma horizontal, descentralizada e rápida. E, ao contrário de outras mídias massivas, viabiliza a participação imediata dos usuários na produção e difusão de informações. Permite, ainda, a formação e manutenção de vínculos entre as pessoas, mesmo sem contatos face-a-face. Assim, o espaço deixa de ser elemento de fricção para as relações sociais e barreira para contatos entre pessoas de diferentes culturas.

Pesquisa realizada no Facebook durante as manifestações ocorridas em junho de 2013, com foco em São Paulo(Pimental \& Silveira, 2013), identificou que o compartilhamento de material postado nos sites ou perfis de grandes jornais diminuiu, à medida que aumentava o compartilhamento de textos e vídeos em sites e perfis da mídia alternativa (AnonymusBrasil, Movimento Contra a Corrupção, Itima Hora e Isso é Brasil). E, mais importante: o papel da grande imprensa era praticamente unilateral, limitando-se a prover informações e sendo incapaz de articular e mobilizar outros atores: "[...] usam as redes à maneira do broadcast, não interagem com outros atores, citam apenas a si mesmos, não ecoam outras narrativas” (Pimental \& Silveira, 2013, s/p).

Mesmo como fonte de informação, a mídia convencional ficou devendo à mídia alternativa, pois o material produzido pelos próprios manifestantes acabou se tornando umamaior fonte de difusão de notícias. Os vídeos produzidos no calor da hora e divulgados no Youtube, por exemplo, superaram as notícias divulgadas nos portais dos grandes jornais. Além da ampla cobertura, as imagens repercutiram na prática dos manifestantes, na medida em que contribuíram para aprofundar a indignação e para despertar solidariedade. Pode-se dizer que as manifestações terminaram por pautar a mídia, e não o contrário (Pimentel \& Silveira, 2013).

\section{Conclusões}

É difícil chegar a conclusões definitivas quando se analisa uma ação coletiva inédita, que rápida e inesperadamente tornou-se massiva, como foram as jornadas de junho de 2013 no Brasil. O ineditismo do fenômeno fica ainda mais acentuado quando comparado a movimentos sociais e protestos de épocas diversas (a ditadura, o período da redemocratização e os governos neoliberais). A conjuntura atual também é inédita: trata-se da hegemonia de um partido que ascendeu ao poder com o apoio da esquerda e dos MS, mas cuja atuação é ambivalente. Lula e Dilma Rousseff realizaram políticas sociais de largo alcance para minorar a pobreza, permitindo a integração de largos contingentes da população ao consumo; contudo, sua contribuição para melhorar o acesso a bens e serviços públicos de qualidade (educação, saúde, transportes, habitação etc.) deixou a desejar.

O modelo desenvolvimentista adotado favoreceu os setores 
imobiliário, automobilístico e da construção civil, com consequências negativas para o meio ambiente e a qualidade de vida nas cidades. No plano político-institucional, os governos petistas abriram mão de convicções ideológicas e do compromisso com a ética na política, para aderir a velhas práticas do pemedebismo, a fim de assegurar maiorias parlamentares. É indispensável levar em conta esse contexto socioeconômico e político, reconhecendo, porém, que ele é apenas um dos elementos para interpretar as ações coletivas que se articularam na sociedade.

A análise das jornadas de junho de 2013, aqui apresentada, buscou contribuir para oferecer uma abordagem teórico-metodológica não para prever, mas para compreender a emergência de protestos massivos e repentinos. Acentuou-se a necessidade de buscar o seu lado "invisível", que se constrói nas entrelinhas da cultura política, a partir do compartilhamento de valores e práticas divergentes da ordem instituída. Assim, movimentos como o MPL e a Articulação dos Comitês Populares da Copa foram além de suas demandas específicas e mostraram a relação destas com a democratização da esfera pública e efetivação de direitos sociais, particularmente o direito à cidade.

Há também outro elemento a considerar, ainda menos visível: o descontentamento que precede a ação coletiva, e que tem relação direta com a conjuntura política e socioeconômica. Os protestos de junho de 2013 propiciaram uma oportunidade para que esse descontentamento se transformasse em indignação, a qual, por sua vez, foi potencializada pela falta de legitimidade ou incapacidade dos canais institucionais para dar vazão a esse sentimento, até então difuso. Isso explica, em grande parte, a multiplicidade de pautas e a heterogeneidade, inclusive ideológica, dos participantes.

A indignação encontrou duas alternativas para se expressar: a Internet e as ruas. Já os movimentos sociais foram, em grande parte, o fermento dos protestos massivos, inéditos em seu formato horizontal e na multiplicidade de pautas. O uso intenso da CMC permitiu articular os participantes das manifestações e divulgar denúncias instantâneas, transformando-se num contraponto à grande mídia. Entretanto, a CMC não foi um deus ex machina das jornadas de junho de 2013; na verdade, ações online e offline se retroalimentaram para fomentar os protestos: como dizia um cartaz, "saímos do Facebook".

As grandes manifestações não se repetiram durante a Copa de 2014. As obras previstas para o evento continuaram, assim como a corrupção e a má qualidade dos serviços públicos. A indignação não explodiu de novo nas ruas, mas é provável que os movimentos sociais, em sua relativa invisibilidade, estejam gestando novas "surpresas". 


\section{Notas}

${ }^{1}$ As ideias que deram origem a este trabalho foram discutidas no evento Reflexões $e$ debates sobre o Brasil em movimento, promovido pelo Departamento de Ciências Sociais da UFC em julho de 2013. A pesquisa incluiu contatos com participantes das manifestações e, principalmente, levantamento de notícias publicadas na mídia e levantamento bibliográfico.

${ }^{2}$ Chama-se ABC à região limítrofe à cidade de São Paulo, formada pelos municípios de Santo André, São Bernardo do Campo e São Caetano,onde se concentra a indústria metalúrgica.

${ }^{3}$ Alusão à sigla do Partido do Movimento Democrático Brasileiro (PMDB), caracterizado por clientelismo e governismo oportunista.

${ }^{4}$ Esse quadro de hegemonia do PT modificou-se no segundo mandato de Dilma Rousseff, iniciado em janeiro de 2015. Ela derrotou o candidato do PSDB, Aécio Neves, por estreita margem de votos, e defrontou-se com denúncias de favorecimento de empresários em contratos com a estatal Empresa de Petróleo S/A (Petrobrás), em troca de pagamentos a políticos do PT e de outros partidos aliados. Ainda que não tenha sido pessoalmente acusada, a popularidade da presidente despencou para percentuais inferiores a $10 \%$ de aprovação.

${ }^{5}$ Os protestos no Brasil têm especificidades em relação aos seus congêneres em outros países. Não há espaço, aqui, para uma comparação aprofundada entre eles, mas cabe mencionar que o Brasil não apresenta altos índices de desemprego nem foi afetado pela crise de 2008 com a mesma intensidade que os Estados Unidos e países da Europa. Nestes, lutava-se para não perder direitos já conquistados; no Brasil, lutava-se para conseguir ou efetivar direitos (Bringel, 2013).

${ }^{6}$ Tilly (1995, apud Alonso, 2012)distingue dois tipos de grandes repertórios de ação coletiva no Ocidente, a partir de extensa pesquisa em jornais britânicos, cobrindo o período de1758-1820 e 1828-1835: o primeiro incluiria ações diretas violentas (invasões de terras, distúrbios de cerimônias públicas,food-riots), contra questões de expressão local (contra a elevação do preço dos alinentos, resistência à cobrança de impostos e aoalistamento militar, por exemplo). A partir do século XIX, o fortalecimento dos Estados nacionais e a formação da sociedade urbano-industrial dão lugar a um novo repertório, de âmbito supra-local, contemplando a luta pelos direitos de minorias religiosas, contra a escravidão e por reofrmas parlamentares. As formas de ação são menos violentas e mais difundidas: formação de associações e sindicatos, passeatas, greves, comícios. 


\section{Bibliografia}

Alexander, J. C. (1998), “Ação coletiva, cultura e sociedade civil: Secularização, atualização, inversão, revisão e desdobramento do modelo clássico dos movimentos sociais”, Revista Brasileira de Ciências Sociais, v. 13, n. 37, pp. 5-31.

Alonso, A. (2009), “As teorias dos movimentos sociais: um balanço do debate”, Lua Nova, v. 76, pp. 49-86, São Paulo.

Idem (2012), “Repertório, segundo Charles Tilly: história de um conceito”, Sociologia \& Antropologia, v. 02, ano 03, pp. 21-41.

Articulação Nacional dos Comitês Populares da Copa (2012), Megaeventos e violações de direitos humanos no Brasil, disponível em <http:// www.portalpopulardacopa.org.br/index.php?option= com_k2\&view=item \&id=198: dossi\%C3\%AA-nacional-deviola\%C3\%A7\%C3\%B5es-de-direitos-humanos>. Consultado em: 24 jul. 2014.

Benford, R., Snow, D. (2000), "Framing processes and social movements: an overview and assessment”. Annual Reviews of Sociology, n. 26, pp. 611-639.

Bringel, B. (2011), “A busca de uma nova agenda de pesquisa sobre os movimentos sociais e o confronto político: diálogos com Sidney Tarrow”, Política e Sociedade, vol.10. n. 18, pp. 51-73.

Ídem (2013), “Miopias, sentidos e tendências do levante brasileiro de 2013”, Insightinteligencia, n. 62, ano XVI, 2. Trimestre, disponível em: <http:// www.insightinteligencia.com.br/62/PDFs/pdf3.pdf>, consultado em: 15 jul. 2014.

Burke, P. (2002), História e teoria social, Unesp, São Paulo.

Campos, M. P. (2014),Quando os assentados chegaram, Fortaleza, Edições Inesp.

Cardoso, A. (2013), “As jornadas de junho e amercantilização da vida coletiva”, Insight Inteligência.n. 62, $2^{\circ}$ trimestre, pp. 23-30, disponível em: <http://www.insightinteligencia.com.br/62/PDFs/pdf1.pdf>, consultado em:15 jul. 2014.

Castells, M. (2013), Redes de indignação e esperança: movimentos sociais na era da Internet, Zahar, Rio de Janeiro.

Ídem (2011), A questão urbana, Paz e Terra, São Paulo.

Cefaï, D. (2009), “Como nos mobilizamos? A contribuição de uma abordagem 
pragmatista para a sociologia da ação coletiva”, Dilemas, Rio de Janeiro, vol. 2, n. 4, pp. 11-48.

Chauí, M. (2013), “As manifestações de junho de 2013 na cidade de São Paulo”, Mídiafazmal: Análise crítica da mídia, disponível em: <http:// midiafazmal.wordpress.com/2013/06/27/marilena-chaui-sobremanifestacoes-2013-2/>, consultado em: 29 jun. 2013.

Fantástico (2013), Pesquisa de opinião pública sobre os manifestantes. s.l., 25 jun. Disponível em: <especial.g1.globo.com/fantastico/pesquisa-deopiniao-publica-sobre-os-manifestantes/>. consultado em 29 jun. 2013.

Goffman, Erwin. (1974) Frame analysis. Nova York, Harper.

Gohn, Maria da Glória. (2011), Teorias dos movimentos sociais: paradigmas clássicos e contemporâneos, São Paulo, Loyola.

Gondim, L. (1991), “Os movimentos sociais urbanos: organização e democracia interna”,Sociedade e Estado, Brasília,vol. 6, n. 2, pp. 129-149.

Knijnik, E., Lima, L. \& Ortellado, P. (2013). A derrubada do aumento: uma narrativa política. In ... \& Pomar, M.Vinte centavos: a luta contra o aumento. Veneta, São Paulo, pp. 22-221.

Lavalle, A., Castello,G.\& Bichir, R. (2004), “Quando novos atores saem de cena. Continuidades e mudanças na centralidade dos movimentos sociais”,Política \& Sociedade, n. 5, pp. 37-55.

Maricato, E. (2013), “É a questão urbana, estúpido” In Vainer, C. et. al.Cidades rebeldes: Passe Livre e as manifestações que tomaram as ruas do Brasil,Boitempo Editorial, disponível em: <http:// ujceara.files.wordpress.com/2014/01/cidadesrebeldespasselivreeasmanifestac3a7c3b5esquetomaramasruasdobrasil.pdf $>$, Consultado em: 20 julho 3014.

Michels, R. “Oligarchy” (1984), In: Fisher, F. \& Siriani, C. (Orgs.), Organization and Bureaucracy, Filadelfia, Temple University Press.

Melucci, A. (1989), “Um objetivo para os movimentos sociais?”, In Lua Nova, n. 17, p.49-66, São Paulo,disponível em: <http://www.scielo.br/ scielo.php?script=sci_pdf\&pid=S0102-64451989000200004\&lng =en\&nrm=iso\&tlng=pt>, consultado em: 31 jul. 2013.

Moisés, J. Á; Martinez-Allier, V. (1978), “A revolta dos suburbanos ou “Patrão, o trem atrasou”. In: ... et al. (Orgs.). Contradições urbanas e movimentos sociais, Rio de janeiro, Paz e Terra, p. 13-63

Movimento Passe Livre (2013), In Vainer, C. et. al.Cidades rebeldes: Passe Livre e as manifestações que tomaram as ruas do Brasil,Boitempo Edito- 
rial, disponível em: <http://ujceara.files.wordpress.com/2014/01/ cidadesrebeldes-passelivreeasmanifestac3a7c3b5esquetomaramas ruasdobrasil.pdf>, consultado em: 20 julho 3014.

Idem (2007), Carta de Princípios do Movimento Passe Livre, disponível em: <www.mpl.org.br/?q=node/2>, consultado em: 20 jul. 2014.

Nobre, M. (2013),Choque de democracia: razões da revolta, Companhia das Letras, São Paulo.

Pereira, R. H. M.\& Schwanen, T. (2014),Tempo de deslocamento casatrabalho no Brasil (1992-2009): diferenças entre regiões metropolitanas, níveis de renda e sexo, IPEA, Brasília.

Pessoa, I.(2014), Democracia urbana: a gênese metropolitana dos protestos de 2013 no Brasil. Trabalho apresentado no 2014 Congress of the Latin American Studies Association, Chicago, IL May 21 - 24. Disponível em:

. Consultado em: 27 jun. 2014.

Pimentel, T. \&Silveira, S. (2013), “Cartografia de espaços híbridos: as manifestações de junho de 2013”,\#Interagentas- Comunicação digital e Ações em Rede, 11 jul., disponível em: <http://interagentes.net/?p=62>, consultado em: 30 jun. 2014.

Piven, F. \& Cloward, R. (1979), Poor people's movements: why they succeed, how they fail, Vintage Books, New York.

Rodrigues, J. M. (2012), Metrópoles em números: crescimento da frota de automóveis e motocicletas nas metrópoles brasileiras 2001/2011, Observatório das Metrópoles, Rio de Janeiro.

Rolnik, R. (2013),Apresentação - “As vozes das ruas: as revoltas de junho e suas interpretações”, Vainer, C. et al. Cidades rebeldes: Passe Livre e as manifestações que tomaram as ruas do Brasil,Boitempo Editorial, disponível em: <http://ujceara.files.wordpress.com/2014/01/cidadesrebeldespasselivreeasmanifestac3a7c3b5esquetomaramasruasdobrasil.pdf $>$, consultado em: 20 julho 3014.

Romao, W. (2013), As manifestações de junho e os desafios à participação institucional. Boletim de Análise Político-Institucional, Instituto de Pesquisa Econômica Aplicada (IPEA), Rio de Janeiro, v. 4, p. 11-17.

Sader, E. (1988), Quando novos personagens entraram em cena: experiências, falas e lutas dos trabalhadores da Grande São Paulo. Paz e Terra, Rio de Janeiro.

Santos, C. N. F. (1981),Movimentos urbanos no Rio de Janeiro, Zahar, Rio de Janeiro. 
Santos, F. (2013), “Primavera brasileira ou outono democrático?”, enInsight Inteligência.n. 62, $2^{\circ}$ trimestre, pp. 33-38, disponível em: <http:// www.insightinteligencia.com.br/62/PDFs/pdf3.pdf>, consultado em: 15jul. 2014.

Santos Jr., O. \& Montandon, D. (2011),Os Planos Diretores Municipais Pós-Estatuto das Cidades: balanço eperspectivas, Letra Capital, Rio de Janeiro.

Schwarz, R. (2013), “Sobre Cidades rebeldes”, In Vainer, C. et al. Cidades rebeldes: Passe Livre e asmanifestações que tomaram as ruas do Brasil, disponível em: <http://ujceara.files.wordpress.com/2014/01/cidadesrebeldespasselivreeasmanifestac3a7c3b5esquetomaramasruasdobrasil.pdf $>$, consultado em: 20 jul. 2014.

Soares, L. E. (2013), A classe média descobriu a brutalidade policial, que os pobres e negros nunca ignoraram. Polícia tornou-se um dos temas chave nas ruas, disponível em: <http://www.geledes.org.br/areas-de-atuacao/ questao-racial/violencia-racial/19596-a-classe-media-descobriu-abrutalidade-policial-que-os-pobres-e-negros-nunca-ignoraram.>consultado em 30 jul. 2014.

Tilly, C. (2008),Contentious performances. Cambridge University Press, New York.

Idem (1995), Identities, boundaries \& social ties. Paradigm Publishers, Boulder.

Touraine, A. (1989),Palavra e sangue: política e sociedade na América Latina, Unicamp, Campinas.

Vitagliano, L. F. (2013), “Jornadas de junho: três enganos e uma hipótese”,Outras Palavras, 24 out. 2013, disponível em: http:// outraspalavras.net/brasil/jornadas-de-junho-tres-enganos-e-uma-hipotese/ consultado em 29 jun. 2014.

Weber, M. (1991), “A objetividade do conhecimento nas Ciências Sociais”, In: Cohn, G. (Org.). Weber, p. 79-141, Ática, São Paulo.

Wilson, S. M. \& Peterson, L. C. (2002),“The anthropology of online communities”, Annual Review of Anthropology, v. 31, pp. 449-467.

Zibechi, R. (2013), “Debajo y detrás de las grandes movilizaciones”, Observatório Social da América Latina (OSAL), Consejo Latinoamericano de Ciencias Sociales (CLACSO), vol. 19, n. 34, pp. 16-35, Buenos Aires. 